\title{
PROCEDIMENTO PARA EMISSÃO DE CERTIDÃO NO REGISTRO DA CRIANÇA CONCEBIDA POR INSEMINAÇÃO ARTIFICIAL HOMÓLOGA POST MORTEM
}

Rodrigo Vilela Barbosa, Ricardo Gabriel de Araújo

Universidade do Oeste Paulista- UNOESTE, Curso de Direito, Presidente Prudente/SP. E-mail: rodrigo.vilela.barbosa@hotmail.com, ricardoaraujo@unoeste.br

\section{RESUMO}

O exposto trabalho tem por objetivo analisar o procedimento registral do Brasil, apresentar o procedimento registral da criança concebida por inseminação artificial homóloga post mortem e comparar os respectivos. O método aplicado foi o dedutivo legal, baseado na interpretação da legislação, jurisprudências e doutrinas específicas. Conclui-se que por mais vaga que seja a lei em determinados aspectos, relacionados à inseminação artificial post mortem, ampara devidamente $o$ direito de registro da criança a ser considerada como filho legítimo do falecido, podendo ter normalmente a qualificação paterna do mesmo em sua certidão.

PALAVRAS-CHAVES: inseminação artificial post-mortem, procedimento registral.

\section{ABSTRACT}

The objective of the present study is to analyze the Brazilian registry procedure, to present the registry procedure of the child conceived by homologous artificial insemination post mortem and to compare the respective ones. The method applied was the legal deductive, based on the interpretation of the specific legislation, jurisprudence and doctrines. It is concluded that, however vague the law in certain aspects, related to artificial insemination postmortem, duly protects the right of registration of the child to be considered as legitimate son of the deceased, and may normally have the paternal qualification of the same in his certificate.

KEYWORDS: post-mortem artificial insemination, registry procedure. 


\section{INTRODUÇÃO}

Os dias se avançam e consequentemente tudo que nos cerca sofre mudanças e evolução. Assim como a sociedade, a tecnologia tem conquistado avanços significativos na ciência, especialmente para casais que lutam em muitas tentativas para engravidar, não obtendo êxodo por deficiências hormonais dentre outros aspectos que causam a infertilidade. Porém, por meio da inseminação artificial homologa, que é uma técnica de reprodução especificamente entre pessoas casadas, é possível hoje atingir a fertilidade e alcançar o sonho de ter filhos.

Defronte a este avanço muitos casais, e até mesmo solteiros, começaram a se familiarizar com a ideia buscando tratamentos para a concepção do feto. A inseminação acaba se tornando esperançosa até em caso de falecimento do genitor, onde por um momento o sonho de ser mãe foi frustrado.

Entretanto, sabemos que nossa lei não consegue acompanhar esses grandes passos da biociência, deixando algumas lacunas no tocante a inseminação artificial e ao reflexo no registro da criança, fazendo ainda mais minucioso o presente estudo.

Isto posto, o designo deste trabalho é objetivo analisar o procedimento registral do Brasil, apresentar o procedimento registral da criança concebida por inseminação artificial homóloga post mortem e comparar os respectivos.

\section{METODOLOGIA}

O método utilizado foi o dedutivo legal, baseado na interpretação da legislação, jurisprudências e doutrina específicas e também de cunho histórico.

\section{ENTENDENDO AS PRINCIPAIS TÉCNICAS DE REPRODUÇÃO ASSISTIDA}

\section{PRINCIPAIS TÉCNICAS DE REPRODUÇÃO ASSISTIDA E CONCEITOS}

Com auxilio da medicina, atualmente o ser humano encontra meios a serem utilizados quando o querer é reproduzir, ter filhos, tornando o intento árduo na constatação de um déficit hormonal que impossibilita o encontro do espermatozoide com o óvulo, comprometendo total ou imparcialmente a conquista.

De acordo com Scalquette (2010, p.58):

A reprodução assistida é aquela em que o casal recebe orientação de forma a programar a maneira de suas relações, visando à facilitação do encontro do espermatozoide com o óvulo, ainda que esse encontro se dê por meio de relação sexual.

Incorporado a Reprodução Assistida, acham-se métodos variantes para que seja executada a mesma em cada caso, de acordo com a necessidade.

\section{INSEMINAÇÃO ARTIFICIAL}

Como parte do foco principal desta pesquisa, temos a Inseminação Artificial como método mais utilizado nos dias atuais, sendo ainda o mais simples dentre as técnicas existentes de reprodução assistida no Brasil.

O mais simples deles é a Inseminação Artificial Intrauterina - IIU, em que uma quantidade de espermatozoides é introduzida no interior do canal genital feminino com o auxílio de um cateter, sem a ocorrência de relação sexual (SCALQUETTE, 2010, p.70).

Da mesma forma, Donadio, Lopes e Melo (1997) leciona:

As técnicas de Reprodução Assistida Laboratorialmente (RA) incluem principalmente aquelas que manipulam isoladamente os gametas masculinos, depositando-os, preparados, em algum ponto do genital 
feminino e, sem dúvida, aquelas em que ovócitos e espermatozoides são assistidos laboratorialmente, sendo depois transferidos os zigotos ou préembriões consequentes.

\section{INSEMINAÇÃO HOMÓLOGAS E HETERÓLOGAS}

Baseando-se nos ensinamentos de Aldrovandi e França (26/03/2012), dependendo da origem dos gametas, a fecundação ou inseminação poderá ser homóloga ou heteróloga:

Dependendo da origem dos gametas, a inseminação ou fecundação será homóloga ou heteróloga. Será homóloga quando a fecundação se der entre gametas provenientes de um casal que assumirá a paternidade e a maternidade da criança. Será heteróloga, quando o espermatozóide ou o óvulo utilizado na fecundação, ou até mesmo ambos, são provenientes de terceiros que não aqueles que serão os pais socioafetivos da criança gerada.

\section{PROCEDIMENTO PARA EMISSÃO DE CERTIDÃO NO REGISTRO TRADICIONAL X REGISTRO DA CRIANÇA CONCEBIDA POR INSEMINAÇÃO ARTIFICIAL HOMÓLOGA POST MORTEM}

Derradeiramente, não se havia regramento no tocante ao registro do concebido por reprodução assistida. Este deveria ser realizado por via judicial, ou seja, através de uma decisão judicialmente proferida. " A medida dá proteção legal a uma parcela da população que não tinha assegurado o direito mais básico de um cidadão, que é a certidão de nascimento" ministra Nancy Andrighi. Corregedora Nacional de Justiça. Façamos então um comparativo entre os respectivos procedimentos.

\section{PROCEDIMENTO PARA EMISSÃO DE CERTIDÃO NO REGISTRO TRADICIONAL (PROVIMENTO CG №41/2012)}

O documento básico a ter em mãos para o registro é a Declaração de Nascido Vivo (DNV, a famosa folhinha amarela no caso do Estado de São Paulo), que deve ser expedida pela maternidade ou hospital que realizou o parto. Nele constam as informações que aparecerão na futura certidão, como o local, horário do nascimento, tipo do parto, data do nascimento, sexo e etc.

Artigo 31.1 do Provimento no41/2012 da Corregedoria Geral da Justiça diz que, havendo a apresentação da Declaração de Nascido Vivo (DN), a obrigação de declarar o nascimento poderá ser feita por qualquer dos legitimados indicados no art.52 da lei 6.015/73.

No caso de Pais casados no civil, deverá levar até o Cartório de Registro Civil a declaração do parto (DNV), carteira de identidade do declarante e Certidão de Casamento do civil. O nascimento deve ser registrado no lugar do parto ou de residência dos pais no prazo de 15 dias, sendo o pai o declarante e 45 dias, sendo a mãe a declarante.

Sendo os pais casados no civil, basta a presença do pai ou da mãe, com documento de identidade e certidão de casamento, além da Declaração de Nascido Vivo (DNV). Entretanto, se não forem casados no civil, o homem pode fazer o registro munido do seu documento pessoal e do documento da mãe da criança, além da DNV.

Em caso de o pai estar ausente, ele pode reconhecer a paternidade por meio de uma declaração com firma reconhecida, ou concedendo procuração específica e registrada em cartório para que se faça o registro.

A partir de 2017, através de parceria com a Receita Federal, os Cartórios estão habilitados e obrigados a emitir CPF (Cadastro de Pessoa Física) no ato do registro de nascimento. Para a emissão, é necessário que seja apresentado documento oficial (RG, CNH ou CTPS) onde conste o 
no do CPF dos pais da criança. O CPF dos pais também deverá estar regular junto a Receita Federal.

PROCEDIMENTO PARA EMISSÃO DE CERTIDÃO NO REGISTRO DA CRIANÇA CONCEBIDA POR INSEMINAÇÃO ARTIFICIAL HOMÓLOGA POST MORTEM (PROVIMENTO CNJ № 52/2016REGISTRO DE NASCIMENTO E EMISSÃO DA RESPECTIVA CERTIDÃO DOS FILHOS HAVIDOS POR REPRODUÇÃO ASSISTIDA)

Este provimento trouxe grande evolução no Direito Civil, regulando dentre suas peculiaridades o registro nas hipóteses de reprodução assistida post-mortem, o primordial foco nesta pesquisa.

A documentação necessária é semelhante ao registro tradicional.

Tomemos nota, conforme Art. 2ㅇ do Provimento no52/2016 da CG:

É indispensável, para fins de registro e da emissão da certidão de nascimento, a apresentação dos seguintes documentos:

I- Declaração de nascido vivo- DNV;

II- Declaração, com firma reconhecida, do diretor técnico da clínica, centro ou serviço de reprodução humana em que foi realizada a reprodução assistida, indicando a técnica adotada, o nome do doador ou da doadora, com registro de seus dados clínicos de caráter geral e características fenotípicas, assim como o nome dos seus beneficiários;

III-Certidão de casamento, certidão de conversão de união estável em casamento, escritura pública de união estável ou sentença em que foi reconhecida a união estável do casal.

Além disso, o referido provimento inova regulamentando a hipótese da reprodução assistida post-mortem, onde no momento do registro, deve ser apresentado o termo de autorização prévia lavrado por instrumento público relatando o consenso para o uso do material biológico preservado.

Provimento no52/2016:

§3ㅇ Nas hipóteses de reprodução assistida post-mortem, além dos documentos elencados acima, conforme o caso, deverá ser apresentado termo de autorização prévia específica do falecido ou falecida para o uso do material biológico preservado, lavrado por instrumento público.

Havendo presente todos os documentos acima elencados, o Oficial Civil não poderá se opor a lavrar o registro, omitindo assim a emissão da certidão.

Entretanto, nos casos em que não houver autorização prévia do genitor, a discussão deverá ser feita via judicial com direito a ampla defesa e contraditório, postergando-se o registro com expresso mandado judicial.

Haja vista que o Art.3ㅇ do presente Provimento veda aos Oficiais registradores a recusa ao registro de nascimento e emissão da respectiva certidão para os filhos havidos por técnicas de reprodução assistida.

\section{CONCLUSÃO}

Conclui-se assim, que por mais vaga que seja a lei em determinados aspectos, relacionados à inseminação artificial post mortem, atualmente ampara devidamente o direito de registro da criança concebida por meio de inseminação homóloga post-mortem a ser considerado como filho legítimo do falecido, podendo ter normalmente a qualificação paterna do mesmo em sua certidão, a qual deverá ser devidamente emitida, desde que presentes os documentos necessários. 


\section{REFERÊNCIAS}

ALDROVANDI, Andréa; FRANÇA, Danielle Galvão de (2012). A reprodução assistida e as relações de parentesco. E-GOV. Disponível em: <http:www.egov.ufsc.br/portal/conteudo/reproducaoassistida-e-relacoes-de-parentesco>. Acessado em 16 de agosto 2017.

Baby Center, COMO REGISTRAR O BEBE. Disponível em: <http: brasil.babycenter.com/a2400010/como-registrar-o-beb\%C3\%>. Acessado em 16 de agosto de 2017.

BRASIL. CG. Resolução no41/2012. Normas de serviço da Corregedoria Geral da Justiça - Registro Civil - minuta de provimento de atualização do capítulo XVII do tomo II. Disponível em: <http://www.arpensp.org.br/?pG=X19leGlizV9ub3RpY2lhcw==\&in=MTczOTc=>. Acessado em 16 de agosto de 2017.

BRASIL. CNJ. Resolução no52, de 14 de março de 2016. Dispõe sobre o registro de nascimento e emissão da respectiva certidão dos filhos havidos por reprodução assistida. Disponível em: <http://www.cnj.jus.br/files/conteudo/arquivo/2016/03/6bd953c10912313a24633f1a1e6535e1.p df $>$. Acessado em 16 de agosto de 2017.

CORRÊA, Marilena; COSTA, Cristiano. Reprodução assistida. Disponível em: <http://www.ghente.org/temas/reproducao>. Acessado em 26 de maio de 2017.

DONADIO, Nilson; LOPES, Joaquim Costa; MELO, Nilson. Reprodução humana II. 1a Ed. São Paulo: Organon, 1997.

MICHALIZYN, Sérgio Mário; TOMASINI, Ricardo. Pesquisas orientações e normas para elaborações de projetos, monografias e artigos científicos. Petrópolis: Vozes, 2005.

OLIVEIRA, Deborah; BORGES JR., Edson. Reprodução assistida: até onde podemos chegar? : compreendendo a ética e a lei. São Paulo: Gaia, 2000.

OFíCIO DO REGISTRO CIVIL, TÍTULOS E DOCUMENTOS E PESSOAS JURÍDICAS DE BLUMENAU/SC. Disponível em: <http://www.registrocivilblumenau.com.br/documentos-necessarios-pararegistro-de-nascimento>. Acessado em 16 de agosto de 2017.

SCALQUETTE, Ana Claudia. Estatuto da Reprodução Assistida. 1ạ Ed. Saraiva, 2010. Disponível em: https:integrada.minhabiblioteca.com.br/books. Acessado em 26 de maio de 2017.

SEMIÃO, Sérgio Abdalla. Os direitos do nascituro: aspectos cíveis, criminais e dobio direito. 2a Ed. Belo Horizonte: Del Rey, 2008. 